\title{
INVERSION OF $T$ WAVES AFTER LONG PAROXYSMS OF TACHYCARDIA
}

\author{
BY \\ MAURICE CAMPBELL \\ From the Cardiographic Department, Guy's Hospital \\ Received February 4, 1942
}

For several years I have been struck by odd cases where changes in the $T$ waves and even sharp inversion of these waves after long paroxysms of tachycardia-in appearance suggestive of coronary occlusion or at least of coronary disease-seemed from the subsequent course of the patient to be no more than the effect of the long paroxysm. Sometimes when these changes were observed it was difficult to exclude active though undiagnosed myocardial disease, such as might follow a silent cardiac infarct; and sometimes the patient had taken digitalis or quinidine in an effort to arrest the attack in such amounts that these might possibly have caused the $T$ wave inversion, though considering the dosage and the short time for which the drug was taken this seemed most unlikely.

In a recent paper (Campbell, 1939) two illustrations of such changes were given with the legend " changes produced by a paroxysm, but simulating the changes after cardiac infarction."

In the first there was a fairly deep inversion of $T$ of the "coronary" type in lead I with a correspondingly high $\mathrm{T}$ in lead III, two days after a paroxysm. After another two days these had both diminished, and three weeks later had returned to normal, the $T$ wave being small but upright in lead $I$ and flat in lead III (Fig. 21, A, B, and C, loc. cit.). This was from a patient who started having paroxysms after diphtheria, and appeared in good health in the intervals.

In the second there was inversion of the whole $S-T$ interval (perhaps of a less obvious coronary type) in leads II and III, one day after a long paroxysm; eleven days later these effects had greatly diminished and eighteen days later they had completely disappeared (Fig. 22, A-D, loc. cit.). This was from a man, aged 40, whose attacks had been present for at least fifteen years, leaving him without any disability between times in the earlier period, but with some gradually increasing dyspnœa in the later period.

In neither case was it thought likely that the change was due to a cardiac infarct or to coronary disease-partly on clinical grounds, and partly because of the speed with which the change was reversed after the attack, But both these patients died, one suddenly and one with congestive failure, so that it was difficult to exclude with certainty coronary disease or organic myocardial 
changes as the cause, though in the case in which there was an autopsy, no coronary disease was found.

The question is of real importance, because after a long paroxysm of tachycardia, a patient is likely to seek advice about the condition of his heart and this is increasingly likely to lead to an electrocardiogram being taken. When there are changes in the $T$ waves or in the $S-T$ interval suggestive of myocardial disease, it is most important that these signs should not be taken as definitive evidence of such disease, if in fact they are no more than the aftereffects of the long paroxysm.

Special efforts were therefore made to obtain serial cardiograms shortly after long paroxysms from patients in whom the length of history of the paroxysms and the absence of any physical signs or symptoms suggesting heart disease made it almost certain that the heart was normal, except for the paroxysms.

First Case. The first patient, where we were fortunate enough to get the chance of taking such records, had started having typical paroxysms when she was 17 , at first only lasting for an hour or two, every three months or so. When she came under my observation, aged 34 , she was a healthy looking woman, with four children, and young for her years. Her attacks had become more frequent and lasted longer, up to 8 or even 16 hours. Since then she has been under my regular observation for another twelve years, and still, after this length of time shows no evidence of heart disease. During all this time she has averaged about ten attacks a year, lasting generally from 8 to 16 hours. Further details need not be given as a full account of her attacks was given in Table IX in the article already referred to (Campbell, 1939), and Fig. 12, 13, and 18 were taken from her. At no time has any abnormal physical sign been found, nor any evidence of heart disease except the paroxysms, though when they lasted for more than six or seven hours, she generally got anginal pain of increasing severity as they continued. Considering the rate of her attacks (about 220) she was not excessively incapacitated and had travelled some miles to see me in attacks, because in the earlier stage they could be stopped by pressure on the neck. In more recent years they have caused greater incapacity but one could hardly expect a woman at 45 to stand them as easily as at 30 , and I do not think this need be taken as evidence of any heart disease. Incidentally she is a patient in whom treatment has been quite ineffective in controlling the incidence of her paroxysms - treatment with bromides, carminatives, digitalis, and quinidine having been tried. She has written to me within the last few weeks: even a period in the East End of London during the worst of the air raids had not upset her unduly, and on the whole her attacks had been less during the war than during the preceding years.

In October, 1938, we were able to get her admitted to hospital in an attack that had lasted three days. Pressure in the neck, 10 grains of quinidine sulphate, and $20 \mathrm{mg}$. of mecholyl, given intramuscularly, did not arrest the attack, which stopped after about six hours in bed.

Serial electrocardiograms after this paroxysm provided a good illustration, 
with transient $T_{3}$ inversion, not unlike that seen after a cardiac infarct. The day after the paroxysm ended there was sharp $T_{3}$ inversion of the cove-shaped type (Fig. 1B) with a flattened $T_{2}$. The next day this was much less, but $T_{3}$

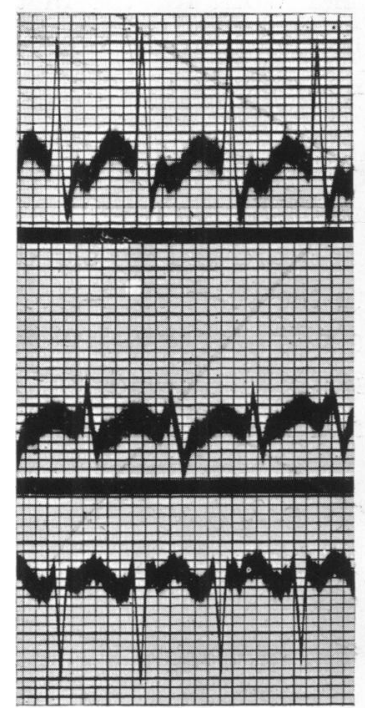

A

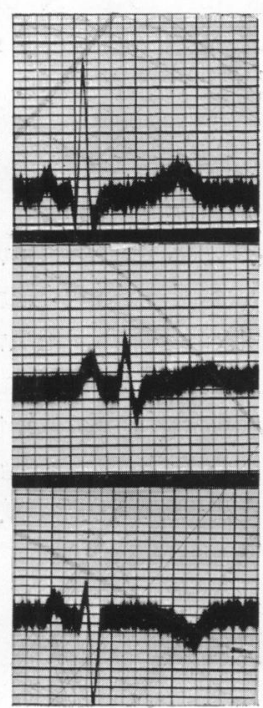

B

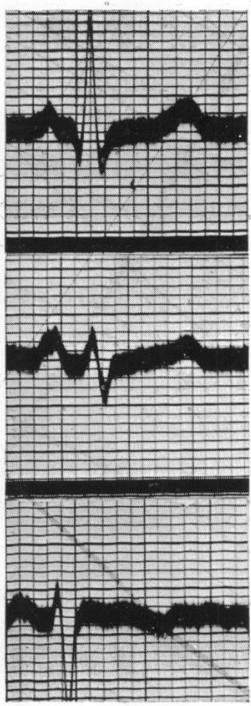

$\mathrm{C}$

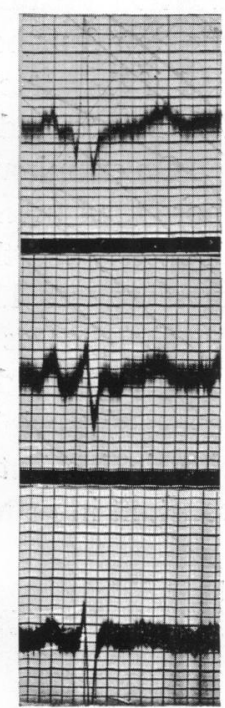

$\mathrm{D}$

FIG. 1._- "Coronary" $T$ wave changes in lead III, one day after a long paroxysm, in a woman with a normal heart and a history of paroxysms for many years.
(A) Paroxysm of tachycardia (6/10/38).
(B) Inversion of $\mathrm{T}$ in lead III, one day later (7/10/38).
(C) Diminishing inversion of T in lead III, three days later (10/10/38).
(D) Disappearance of all inversion of T in lead III, six days later (13/10/38).

was still just inverted (Fig. 1C), and three days later the inversion had completely disappeared, (Fig. 1D).

It seems improbable that after some hundreds of attacks spread over 30 years one should have recorded an exceptional one that was really due to some serious coronary episode; on the contrary, as the attack to her and to other observers seemed the same as all the others it is almost certain that such changes in the $T$ waves occurred frequently whenever an attack was of sufficient length.

Second Case. During the same month, we obtained inconclusive records from another patient (Fig. 3) in whom we suspected similar changes (Fig. 2), but within two months after a longer attack we got most satisfactory evidence in her case also (Fig. 4). This second patient, who was first seen in 1932 when she was 44 , had suffered from paroxysmal tachycardia since 17 years of age. She had diphtheria at 13 , but no rheumatic fever, chorea, or rheumatism. The paroxysms were characteristic, and have since been confirmed graphically (Fig. 3A). From the age of 17 to 44, she was never six months without an attack and often had two a week. In 1932 she had fourteen attacks mostly lasting between 12 to 24 hours. In general they had lasted from 12-48 hours, though 
some were shorter, and one, when she was 21 , was said to have lasted for two weeks, and another, when she was 35 , for three weeks. Bending or stretching were liable to start attacks and she was afraid of hurrying or sudden exertion because of them. She was able to carry on her work for the first three or four hours of an attack, but then generally felt she had to lie down, and if the attack was long, felt tired for a few days. Between the attacks she was able to lead a normal life.

On examination, nothing abnormal could be found. She was thin, but not more than usual. Her heart was not enlarged $(12.0 \mathrm{~cm}$. maximum transverse diameter) and the shape was normal. No murmurs were heard and the blood pressure was 130/80. At frequent examinations during the years 1932-1939 no change was observed. Her electrocardiogram was a little unusual with sharply pointed $\mathrm{P}_{2}$, a notched upstroke of $\mathrm{R}$ in leads II and III, and some tendency to right axis deviation; part of the S-T interval was below the isoelectric line, but there was no inversion of the $\mathrm{T}$ waves. All these features were constant in many cardiograms taken between 1932-1938 (Fig. 2, A and B).

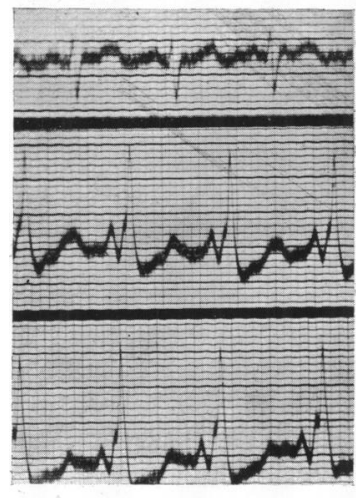

A

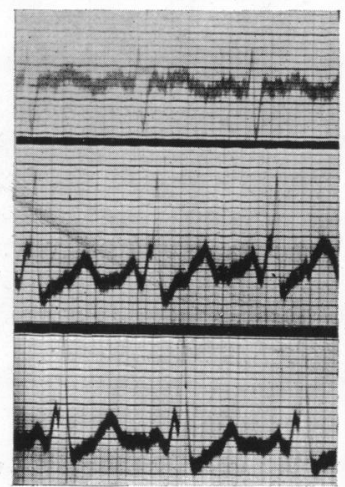

B

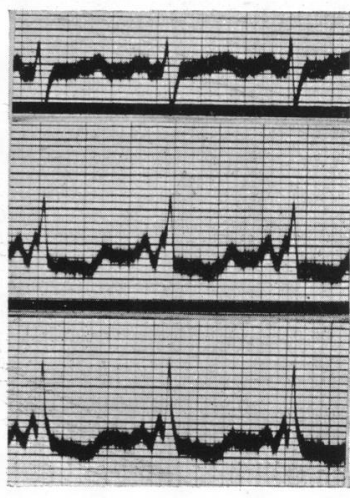

C

FIG. 2.- Increased inversion of the S-T period in leads II and III after a paroxysm of tachycardia.

(A) Normal for this patient $(7 / 12 / 32)$.

(B) Normal, later (16/11/34).

(C) Some partial inversion of S-T in leads II and III, 5 days after a paroxysm (29/9/38).

In 1935, after an attack lasting six days, she started taking quinidine, 3 grains b.i.d., and had no attack for four months, and then one during each of the next three months, lasting 36,48 , and 17 hours.

She was seen again in September, 1938, having kept an exact record of her four attacks in seven months as follows: March, one of 5 days, 14 hours; June, one of 4 days, 1 hour; August, one of 5 days, 23 hours; and September, one of 5 days, 22 hours. The year had been unusual in the number of long attacks and the absence of shorter ones. Quinidine, as taken in small doses at home, did not appear of value in stopping the attacks, and the absence of short attacks was not due to her taking it regularly, though this seemed to have helped at first. 
There was no increase in the size of the heart since 1932, no change of murmurs, and no rise of blood pressure, but the lower T waves in leads II and III (see Fig. 2C) in a cardiogram taken five days after this attack had stopped, made me decide to try to get records just after an attack in which she had taken no digitalis or quinidine, to see if myocardial change was developing or if this was another example of $\mathrm{T}$ wave changes after a paroxysm.

On October 11 she came to hospital after an attack which had lasted 8 hours; it was recorded (Fig. 3A) and stopped 17 minutes after she had been given

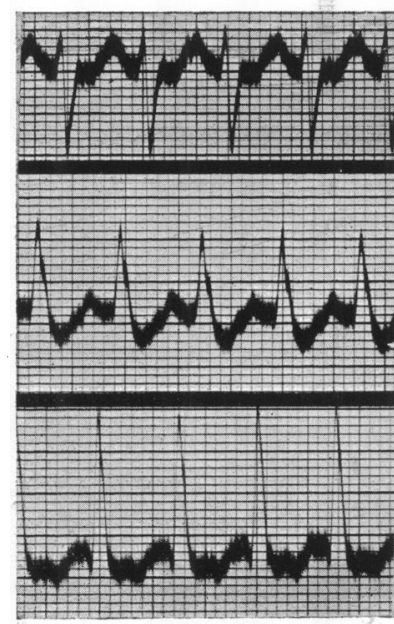

A

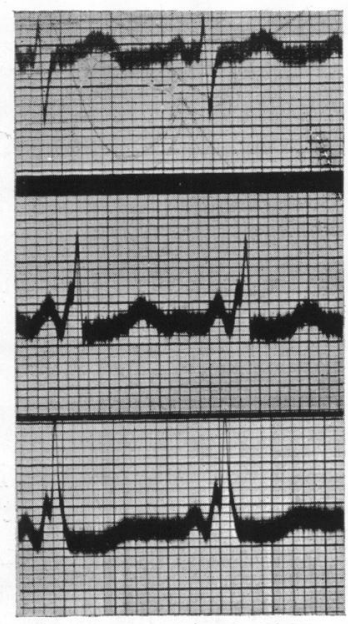

B

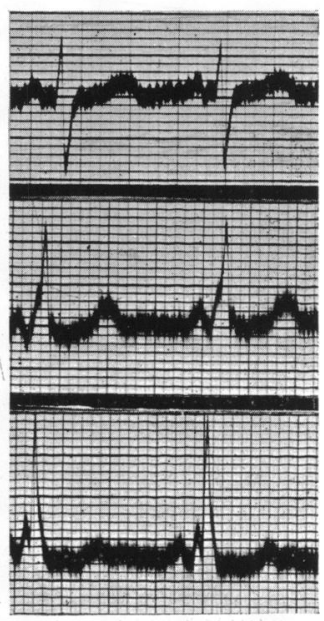

C

Fig. 3.-Showing the absence of anything more than minor changes after a shorter paroxysm in the same patient.

(A) Paroxysm of ten hours (11/10/38).

(B) Slight diminution of the voltage of S-T in leads II and III, two days later (13/10/38).

(C) Practical return to normal four days later (17/10/38).

$1.5 \mathrm{mg}$. of prostigmin intramuscularly. A cardiogram taken two days later showed no change in the $\mathrm{T}$ waves except that more of $\mathrm{S}-\mathrm{T}_{3}$ was below the isoelectric level (Fig. 3B); after another four days this was back nearer to her normal (Fig. 3C).

On December 19, the day after an attack which had lasted six days and stopped 45 minutes after her second dose of 5 grains of quinidine (the first being two hours before), there was inversion of $T$ in all leads, especially $T_{1}$ and $T_{2}$ and $T_{1}$ was almost cove-shaped (Fig. 4A). Three days later, $T_{1}$ was becoming upright, but $T_{2}$ was still inverted and $T_{3}$ was more inverted (Fig. 4B). A week later, and still more two weeks later (Fig. 4, C and D), the $T$ waves had returned practically to her normal.

This attack seemed to her just the same as those that she had had for many years and her condition was unchanged after it.

These two patients seem specially good examples of the condition described, in that they have been under observation so many years with their paroxysms without any evidence of other heart disease, and it seems most unlikely that 


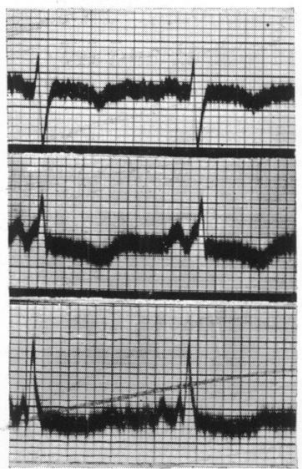

A

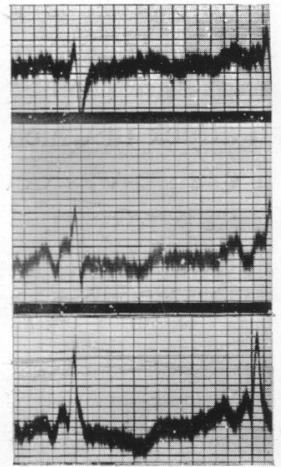

B

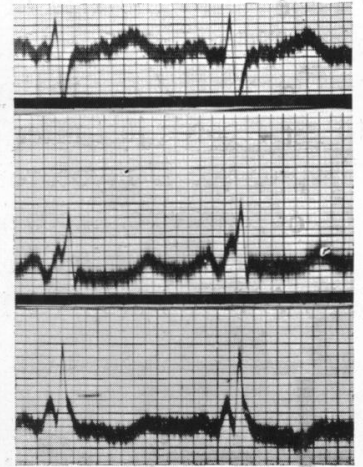

C

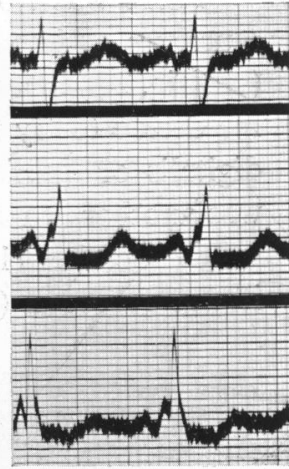

D

FIG. 4.-Inversion of the $T$ waves in all leads in the same patient after a long paroxysm.

(A) Deep inversion of $\mathrm{T}$ in leads I and II, one day after a paroxysm that had lasted six days $(19 / 12 / 38)$.

(B) Disappearance of the inversion of $\mathrm{T}$ in lead $\mathrm{I}$, but increase in the inversion of $\mathrm{T}$ in lead III, $T$ in lead II remaining mainly inverted as before $(22 / 12 / 38)$.

(C) Complete recovery of $\mathrm{T}$ wave in lead $\mathrm{I}$ and disappearance of most of the inversion of $\mathrm{S}-\mathrm{T}$ in leads II and III $(29 / 12 / 38)$.

(D) Further return towards normal $(5 / 1 / 39)$.

a nything recorded after these paroxysms was exceptional for these patients, and that therefore the $T$ wave changes were the result of the length and severity of the paroxysms, and were not due to any acute organic disease of the heart muscle.

Third Case. I am indebted to Dr. John Parkinson for the notes and electrocardiograms of the following case. Although the details are not complete and it was not possible to follow him for long, it seemed worth including, because the changes were so striking and also because they were noted after three separate attacks.

D.S., aged 21, was in three hospitals for at least six weeks with a diagnosis of chronic myocarditis; no details are available as to why this diagnosis was made.

On January 12, 1940, after a month's sick leave, he returned to an R.A.F. station and at once reported sick. His pulse was almost imperceptible at the wrist, and the heart rate at the apex was 174. He said that the condition had started when he was on leave; that he felt breathless and was himself conscious of the rapid beating of the heart; that since the previous October he had suffered from five similar attacks; that all had started suddenly; and that the longest had lasted seven days.

He did not look ill in spite of the attack. Nothing abnormal was found on examination except that the blood pressure was 100/70. A cardiogram confirmed the diagnosis of paroxysmal tachycardia, and as the usual methods failed to stop it, he was given 3 grains of quinidine, after which the heart rate soon dropped to 80 . Fig. 5A, taken the next day, showed deeply inverted $T$ waves in leads II and III, such as one might expect after a large cardiac infarct or some other serious myocardial infection. But his age, the absence of symptoms, the quick recovery, and the recurrence of similar changes after two other attacks, all make this extremely unlikely. Within ten days this deep 
inversion of $\mathrm{T}$ had completely disappeared in lead II, and almost completely in lead III (Fig. 5B).

Another attack started the next day and lasted two days. He was given 33 grains of quinidine and the attack stopped; a cardiogram taken two days later again showed inversion of the $\mathrm{T}$ waves in leads II and III.

Nine days later there was a third observed attack (Fig. 5C), which stopped during his sleep. Although this attack had not lasted long, Fig. 5D, taken on the third day, again showed inversion of $\mathrm{T}$ in leads II and III: though this was

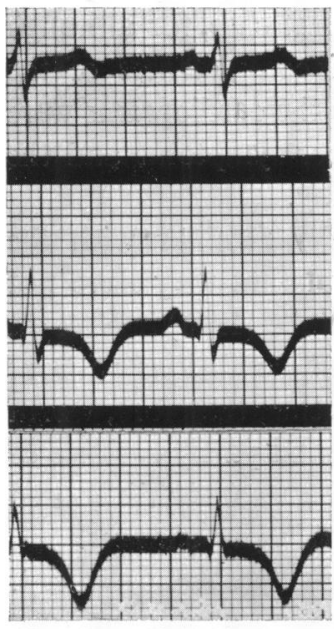

A

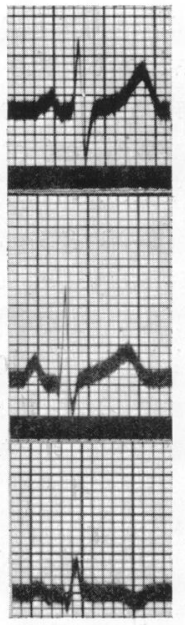

B

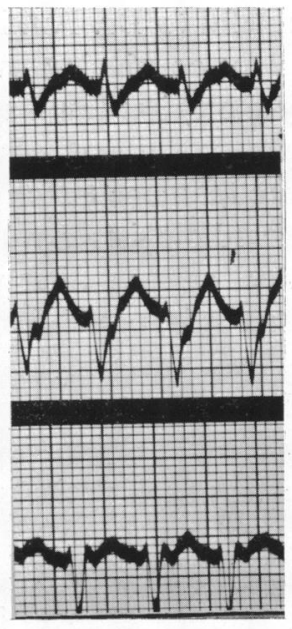

C

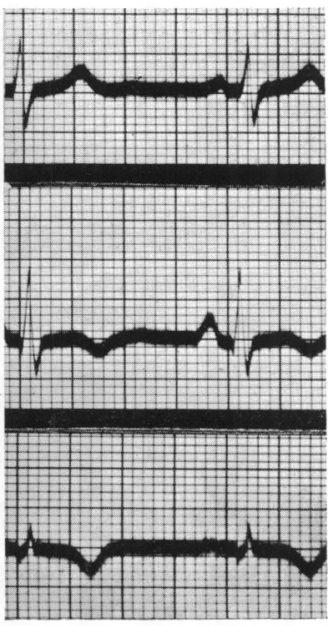

D

FIG. 5. - " Coronary" $\mathrm{T}$ wave changes in leads II and III after paroxysms of tachycardia in a healthy young man.

(A) Cardiogram with deeply inverted T in leads II and III, taken one day after a long paroxysm of tachycardia had stopped. Only one dose of 3 grains of quinidine had been taken (16/1/40).

(B) Return to normal, ten days later $(26 / 1 / 40)$.

(C) Cardiogram ten days later $(5 / 2 / 40)$ of another paroxysm which had stopped spontaneously during the first night.

(D) Recurrent inversion of $\mathrm{T}$ in leads II and III, in cardiogram taken on the third day after another attack $(8 / 2 / 40)$.

not nearly as deep as after the longer attack (Fig. 5A), possibly because it was after a shorter attack, possibly because it was taken three days instead of one day after, or more probably for both these reasons.

A fourth attack was observed a few days later, after which he remained quite fit and free from any attack for a month.

\section{DisCUSSION}

Five cases, two reported previously and three given in more detail here, have been recorded; in all striking changes in the $T$ waves after paroxysms of tachycardia were suggestive of progressive coronary disease such as cardiac infarction. The first two ultimately died and though all the evidence seemed against it, it may be that they really had organic changes underlying these electrocardiographic changes.. It was, therefore, decided to get rēcords in all 
possible patients during the period after their paroxysms of tachycardia, and the first two cases, here reported, were two of the first instances found with such $T$ wave changes; in one they had been suspected previously from earlier records, and in the other there was no previous evidence. It was intended to continue the collection of an additional number of cases to obtain some even more satisfactory records, but the onset of the war has prevented me keeping in touch with the necessary number of patients with paroxysms, and as anyone who is working at the subject will realize with such an erratic condition it always takes a long time to get any particular type of observation that one requires. I was, therefore, most grateful to Dr. Parkinson for the last case, for although alone it might not be very convincing owing to the incompleteness of the history and the relatively short time that has passed since the cardiograms were taken, he was an apparently fit young man without other symptoms and the $\mathrm{T}$ wave changes after more than one attack were so striking.

It is probable that cardiologists have been generally familiar with the occurrence of such $\mathrm{T}$ wave changes after paroxysms, but that they have not obtained enough of such records for publication. Paul White (1941) in a recent article on inversion of the $T$ wave in lead II in various conditions without organic heart disease did not refer to such cases, and it seems, therefore, worth putting on record, partly because of its scientific interest, and partly because of the practical importance that such patients should not be wrongly diagnosed as having organic heart disease because of the temporary $T$ wave changes.

I have no evidence to bring forward as to how these changes are produced: It may be that chemical or other changes in the myocardium as a result of a prolonged attack, are responsible, and in this sense the changes would, to some extent, be a measure as to the severity and seriousness of the attack, and might indicate the need for adequate rest. Another possible explanation is that it depends on changes in the position of the heart, and that as the diaphragm sinks, or as the stomachs empties, the heart returns to its more normal position with the return to its normal electrocardiographic pattern. Although this would bring the cases into line with some of the other $T$ wave changes that have been reported, and admittedly the third of these cases had a mobile heart where changes did influence the electrocardiogram, this explanation seems most unlikely, for one reason because the time taken for recovering from these changes is measured in days rather than hours.

\section{SUMMARY}

After long paroxysms of tachycardia the $\mathrm{T}$ waves may become inverted in one or more leads for some days. This does not indicate any organic disease, but is a completely reversible process indicating some degree of exhaustion or strain of the heart muscle.

\section{REFERENCES}

Campbell, M. (1939). Brit. Heart J., 1, 123. White, P. D., Chamberlain, F. L., and Graybiel, A. (1941). Ibid., 3, 233.

PRINTED IN GREAT BRITAIN BY WILLIAM CLOWES AND SONS, LTD., LONDON AND BECCLES. 